\title{
Assessment of Direct Torque Control of a Double Feed Induction Machine
}

\author{
A.M. Bouhentala. ${ }^{1,2}$ M.S. Benbouza ${ }^{1}$ \\ 1. Department of electrical Engineering Batna University, Rue Med El Hadj Boukhlouf, Batna 05000, Algeria. \\ 2. Laboratoire LEB de Biskra, Algeria.
}

\begin{abstract}
In this paper, we present the application of the control of doubly fed induction machine, using direct torque control (DTC). This method has a simple and robust control structure; the performance of DTC strongly depends on the quality of the estimated actual stator flux and torque. DTC with switching tables provide excellent torque dynamics. The implementation of the DTC applied to a double feed induction motor is validated with simulated results. The results demonstrate that the proposed controller leads to performance improvements despite its simple structure.
\end{abstract}

Key-words: Field-oriented control, induction motors torque control, double-feed induction machine,

\section{INTRODUCTION:}

The apparition of the field oriented control (FOC) made induction machine drives a major candidate in high performance motion control applications. However, the complexity of field oriented algorithms led to the development in recent years of many studies to find out different solutions for the induction motor control having the features of precise and quick torque response. The direct torque control technique (DTC) proposed by I. Takahashi [1] and M. Depenbrock [2] in the mid eighties has been recognized to be a viable solution to achieve these requirements [1]-[5], The scheme, as the name indicates, is the direct control of torque and stator flux of a drive by inverter voltage space vector selection through a lookup table [2].

The three phase induction motor with wound rotor is doubly fed when, as well as the stator windings being supplied with three phase power at an angular frequency $\omega_{s}$, the rotor windings are also fed with three phase power at a frequency $\omega_{r r}$. Under synchronous operating conditions, as shown in [5]-[8], the shaft turns at an angular velocity $\omega_{r}$, such that:

$$
\omega_{r}=\omega_{s}+\omega_{r r}
$$

The sign on the right hand side is (+) when the phase sequences of the three phase supplies to the stator and rotor are in opposition and (-) when these supplies have the same phase sequence. The rotational velocity of the shaft, $\omega_{r}$, is expressed in electric radians per second, to normalize the number of poles.

\section{MODEL OF DOUBLE FEED INDUCTION MACHINE}

The mathematical model for the electrical parts is written as a set of equations of state following:

$$
\frac{d X}{d t}=\dot{X}=A X+B U
$$

$$
X=\left[\begin{array}{c}
I_{r \alpha} \\
I_{r \beta} \\
\Phi_{s \alpha} \\
\Phi_{s \beta}
\end{array}\right] \quad \text { And } \quad U=\left[\begin{array}{c}
V_{s \alpha} \\
V_{s \beta} \\
V_{r \alpha} \\
V_{r \beta}
\end{array}\right]
$$

The matrices $\mathrm{A}$ and $\mathrm{B}$ are given by:

$$
\begin{gathered}
A=\left[\begin{array}{cccc}
\frac{-1}{T_{s}^{\prime} \delta} & \omega_{r} & \frac{1-\delta}{\delta M T_{s}} & \frac{1-\delta}{\delta M} \omega_{r} \\
-\omega_{r} & \frac{-1}{T_{s}^{\prime} \delta} & -\frac{1-\delta}{\delta M} \omega_{r} & \frac{1-\delta}{\delta M T_{s}} \\
\frac{M}{T_{s}} & 0 & -\frac{1}{T_{s}} & 0 \\
0 & \frac{M}{T_{s}} & 0 & -\frac{1}{T_{s}}
\end{array}\right] \\
\mathrm{B}=\left[\begin{array}{cccc}
-\frac{1-\delta}{\delta M} & 0 & \frac{1}{L_{r} \delta} & 0 \\
0 & -\frac{1-\delta}{\delta M} & 0 & \frac{1}{L_{r} \delta} \\
1 & 0 & 0 & 0 \\
0 & 1 & 0 & 0
\end{array}\right]
\end{gathered}
$$

The mathematical model for the mechanical parts is written as the following state equations:

$$
\mathrm{J} \frac{\mathrm{d} \Omega}{\mathrm{dt}}=\mathrm{C}_{\mathrm{em}}-\mathrm{C}_{\mathrm{r}}-\mathrm{K}_{\mathrm{f}} \Omega .
$$

Where $\mathbf{J}$ is the moment of inertia of the revolving parts, $\mathrm{K}_{\mathrm{f}}$ is the coefficient of viscous friction, arising from the bearings and the air flowing over the motor, and $\mathrm{C}_{\mathrm{em}}$ is the load couple.

The equation of the electromagnetic torque is:

$$
C_{e}=\frac{3 p M}{2 L_{s}}\left(\Phi_{s \alpha} I_{r \beta}-\Phi_{s \beta} I_{r \alpha}\right)
$$

Where $\mathrm{X}$ is the state variable and $\mathrm{U}$ is control variable: 


\section{DIRECT TORQUE CONTROL FOR THE DOUBLE FEED INDUCTION MACHINE}

Direct torque control is based on the flux orientation, using the instantaneous values of voltage vector.

An inverter provide eight voltage vector, among which two are zeros.This vector are chosen from a switching table according to the flux and torque errors as well as the stator flux vector position. In this technique, we don't need the rotor position in order to choose the voltage vector. This particularity defines the DTC as an adapted control technique of ac machines and is inherently a motion sensorless control method [9]-[12].

The block diagram for the direct torque and flux control applied to the double feed induction motoris shown in figure 1.The stator flux $\Psi_{\text {ref }}$ and the torque $\mathrm{C}_{\text {emref }}$ magnitudes are compared with respective estimated values and errors are processed through hysteresis-band controllers.

Stator flux controller imposes the time duration of the active voltage vectors, which move the stator flux along the reference trajectory, and torque controller determinates the time duration of the zero voltage vectors, which keep the motor torque in the defined-by hysteresis tolerance band. Finally, in every sampling time the voltage vector selection block chooses the inverter switching state, which reduces the instantaneous flux and torque errors.

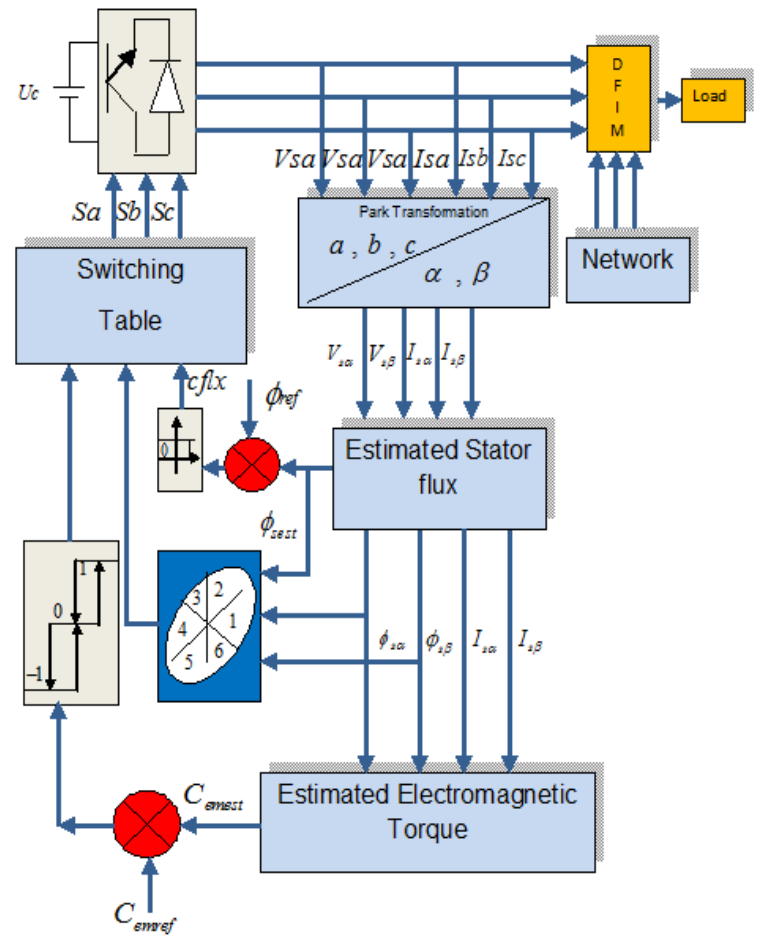

Fig.1 DTC applied to double feed induction machine

\section{SIMULATION RESULTS}

Figure 2 shows in order, the variation in magnitude of the following quantities, speed, flux and electromagnetic torque obtained while starting up the induction motor initially under no load then connecting the nominal load. As can be seen during the starting up with no load the speed reaches rapidly its reference value without overtaking, however when the nominal load is applied a little overtaking is noticed and the command reject the disturbance. The excellent dynamic performance of torque and flux control is evident.
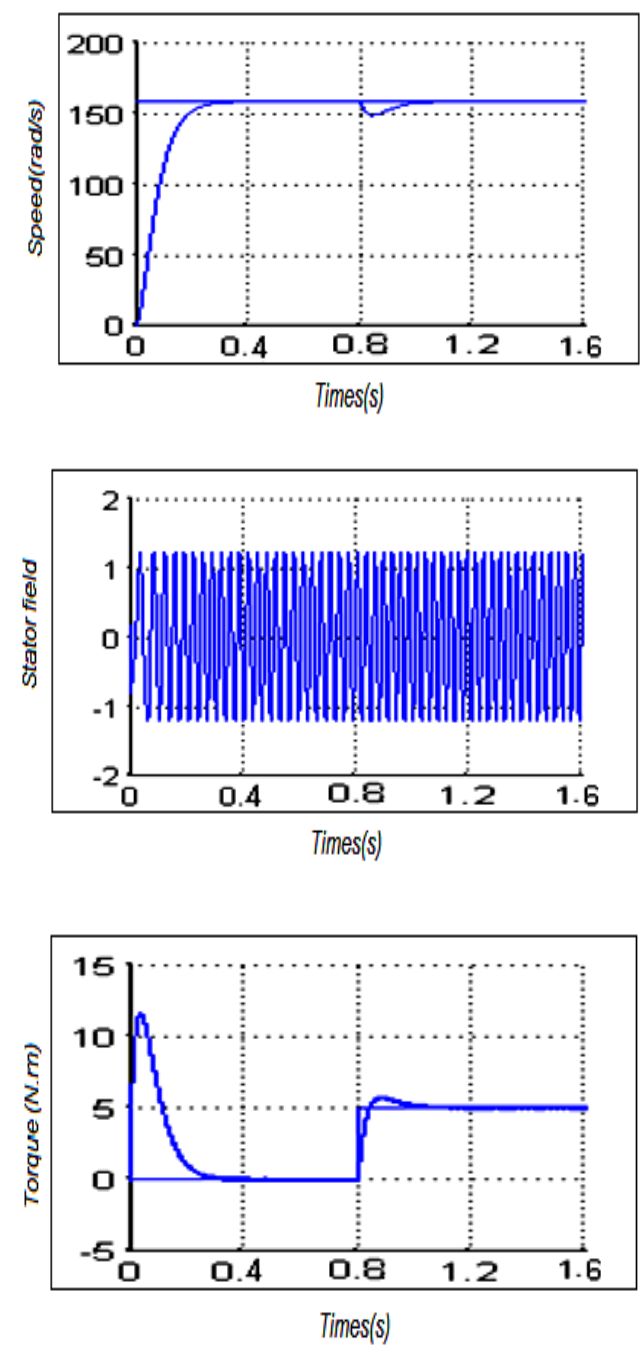

Fig. 2 Simulation results obtained with an IP regulator

\section{CONTROL WITH AN IP REGULATOR}

\subsection{Operation Under variable speed}

The simulation results obtained for a speed variation for the values: $\left(\Omega_{\mathrm{REF}}=157,100\right.$ and $\left.157 \mathrm{rad} / \mathrm{s}\right)$, with the load of 3 N.m applied at $\mathrm{t}=0.75 \mathrm{~s}$ are shown in Figure 3 .

This results shows that the speed variation lead to the varaition in flux and the torque. The response of the system is positive, the speed follow its reference value while the torque return to its reference value with a litte error. 

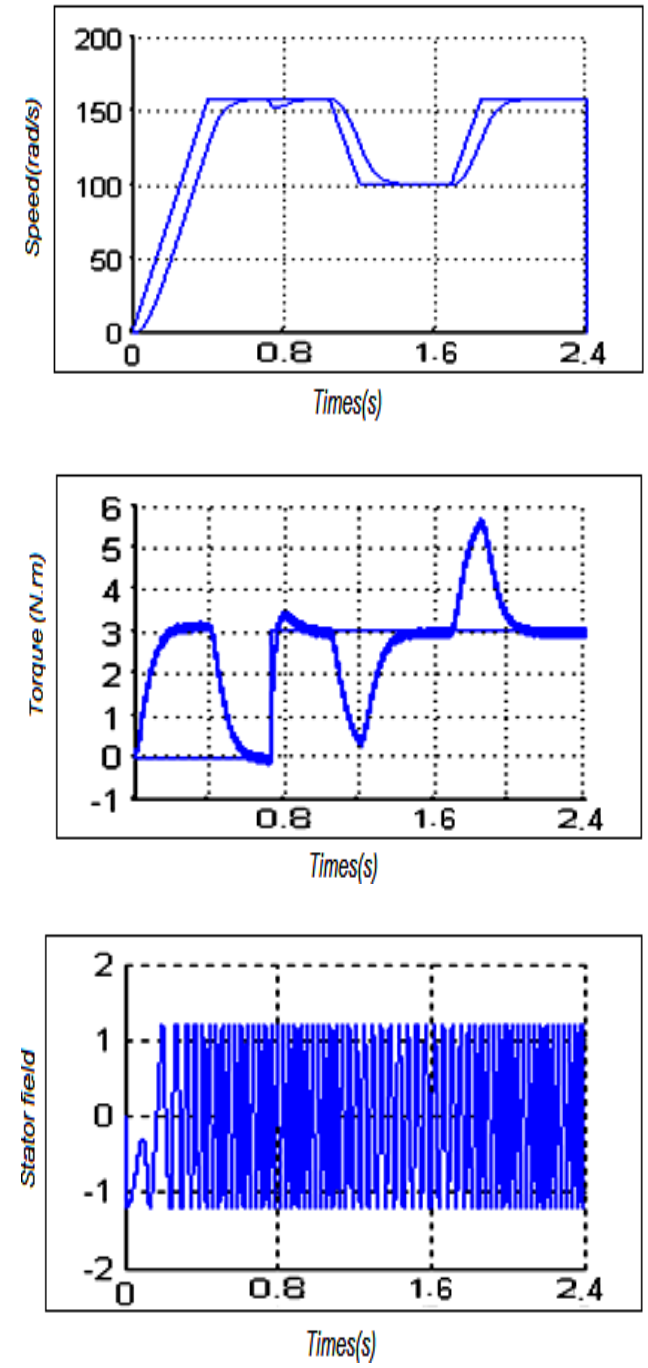

Fig 3. Robust control for a speed variation

\subsection{Operation Under reversal Speed}

In figure 4, the excellent dynamic performance of torque control is evident, which shows torque reversal for speed reversal of $(157,-157 \mathrm{rad} / \mathrm{s})$, with a load of $5 \mathrm{~N} . \mathrm{m}$ applied at $\mathrm{t}=0.8 \mathrm{~s}$. The speed and torque response follow perfectly their reference values with the same response time. However, the reversal speed lead to a delay in the speed response, to a peak oscillation the current as well as a fall in the flux magnitude which stabilise at its reference value.

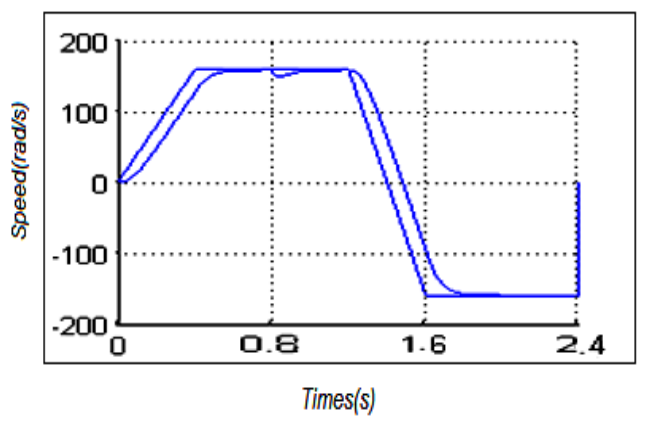

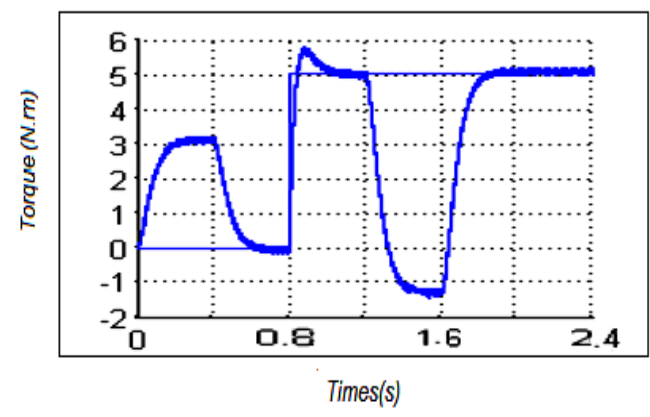

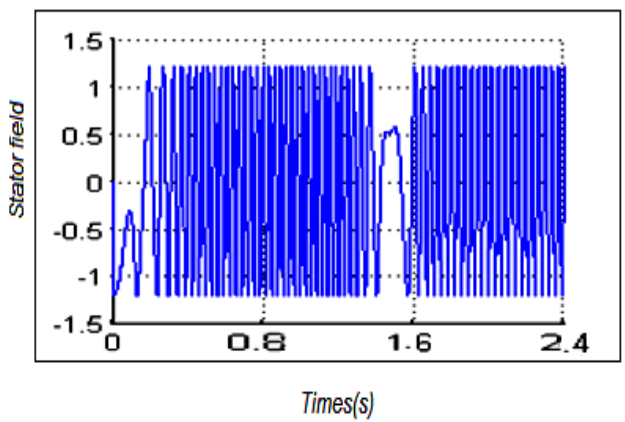

Fig 4. Robust control under reversal speed

\subsection{Operation Under various load conditions}

For a load variation $\left(\mathrm{C}_{\mathrm{r}}=3 \mathrm{~N} . \mathrm{m}, 6 \mathrm{~N} . \mathrm{m}\right)$, the simulation results obtained are shown in figure 5 . As can be seen the speed, the torque and the flux are influated with the load variation. Indeed the torque and the speed follow their refrence values.
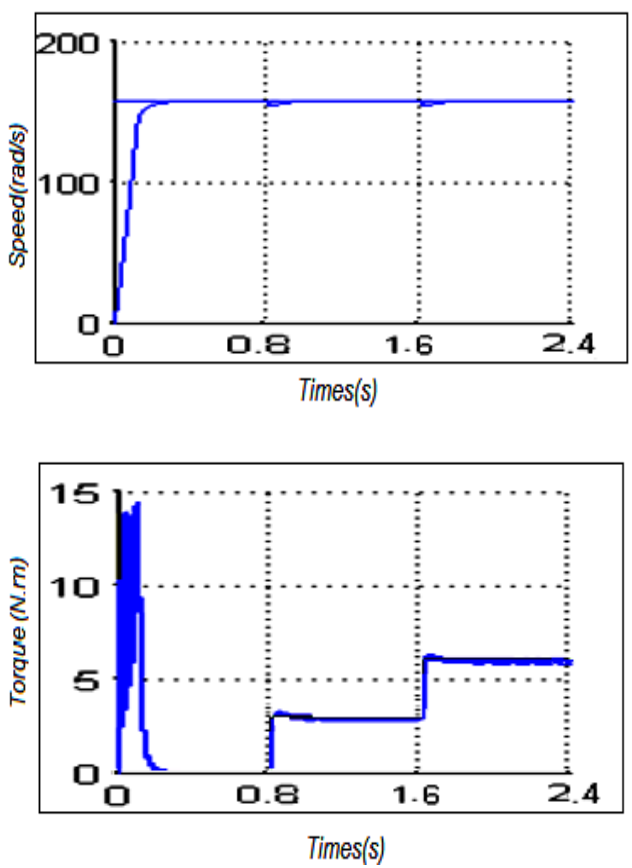


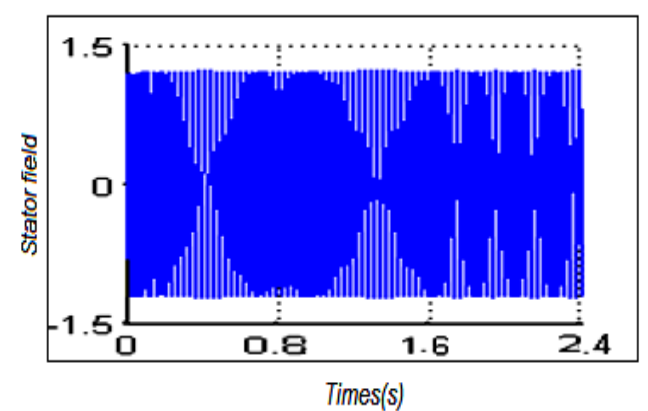

Fig 5. Robust control under load variation

\subsection{Robust control under stator resistance variation}

In order to verifie the robustess of the regulator under motor parameters variations we carried out a test for a variation of $50 \%$ in the value of stator resistance at tile $\mathrm{t}=$ $1.2 \mathrm{~s}$. The speed is fixed at $157 \mathrm{rad} / \mathrm{s}$ and a resistant torque of $5 \mathrm{n} . \mathrm{m}$ is applied at $\mathrm{t}=0.8 \mathrm{~s}$. Figure 6 shows the in order the torque response, the current, the stator flux and the speed..The results indicate that the regulator is very sensitive to the resistance change which results in the influence on the torque and the stator flux
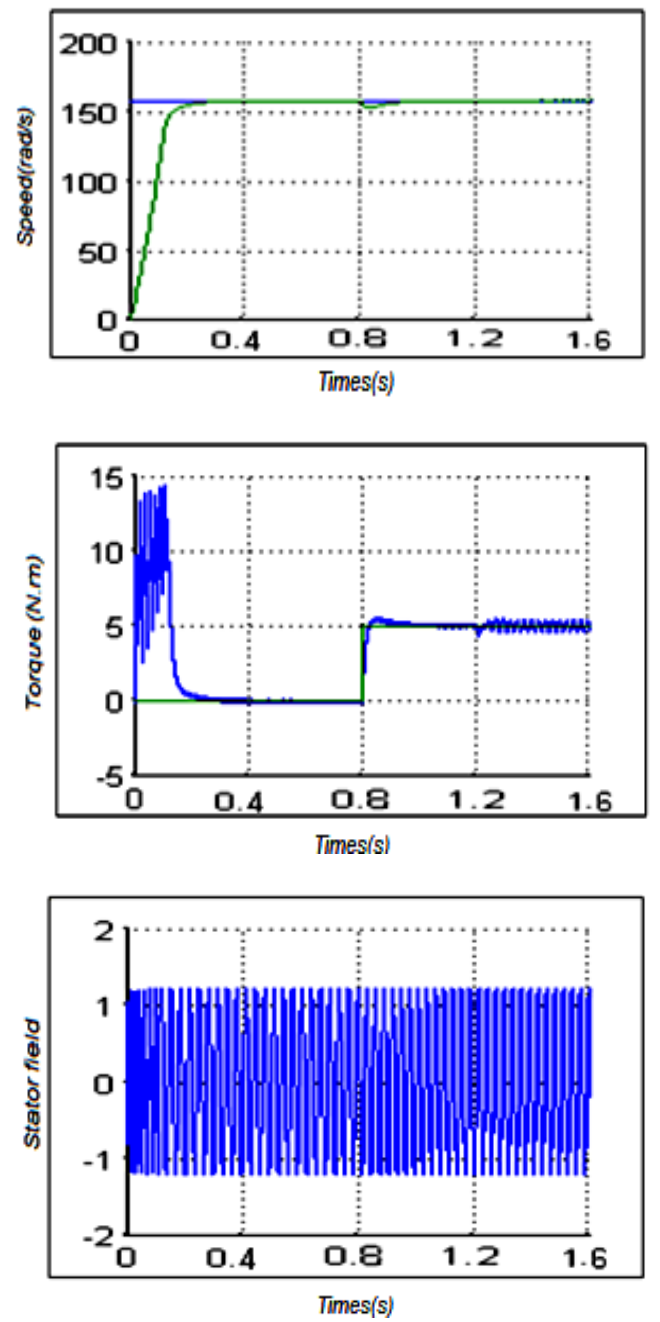

Fig 6. Robust control under stator resistance variation

\section{CONCLUSION}

In this paper, the well-known classical dtc is detailed and applied to double feed induction machine to improve its performance.

The control strategy of the double feed induction machine based on the direct control torque (DTC) use an IP regulator. The simulation results show that the dtc is an excellent solution for general-purpose induction drives in a very wide power range. The short sampling time required by the DTC scheme makes it suited to very fast torque and flux controlled drives in spite of the simplicity of the control algorithm. We believe that the DTC principle will continue to play a strategic role in the development of high performance motion sensorless AC drives. 


\section{REFERENCES}

[1] Takahashi, T. Noguchi, A new quick response and high efficiency control strategy of an induction motor, IEEE Trans. Ind. Applicat., vol. IA-22, pp. 820.827, Sept./Oct. 1986.

[2] M. Depenbrok, Direct self-control (DSC) of inverter fed induction machine, IEEE Trans. Power Electron. vol. PE-3, pp. 420.429, Oct. 1988.

[3] I. Boldea, S. A. Nasar, Torque vector control (TVC).A class of fast and robust torque speed and position digital controller for electric drives, in Proc. EMPS, vol. 15, 1988, pp. 135.148.

[4] T. G. Hableter, F. Profumo, M. Pastorelli, L. M. Tolbert, Direct torque control of induction machines using space vector modulation, IEEE Trans. Ind. Applicat., vol. 28, pp. 1045.1053, Sept./Oct. 1992.

[5] D. Casadei, G. Grandi, G. Serra, Study and implementation of a simpli.ed and efficient digital vector controller for induction motors, in Proc. EMD'9 3, Oxford, U.K., Sept. 8.10, 1993, pp. 196.201.

[6] M. P. Kazmierko wski, H. Tunia, Automatic Control of Converter-Fed Drive, Amsterdam, the Netherlands: Elsevier, 1994.

[7] J. N. Nash, Direct torque control, induction motor vector control without an encoder, IEEE Trans. Ind.Applicat., vol. 33, pp. 333.341, Mar./Apr. 1997.

[8] J.C. PRESCOTT et alii, The Inherent instability of Induction Motor under conditions of Doubly -Supply, IEEE Proceedings, UK, v.105,pp. 319/330.1958.

[9] C. D. Cook and B. H. Smith. Stability and stabilization of doubly-fed single frame cascade induction machines. IEE Proceedings, 126(11):1168-1174, 1979.

[10] C. D. Cook and B. H. Smith. Effects of machine parameter values on dynamic response and stability regions of doubly-fed cascade induction machines. IEE Proceedings - B Electrical Power Applications, 130(2):137-142, 1983.

[11] D. Zhou, R. Spée, and A. K. Wallace. Model reference adaptive speed control for doubly-fed machines, In Proceedings of International Conference on Industrial Electronics, Control and Instrumentation (IECON), volume 2. IEEE, 1993.

[12] P. Vas, Sensorless Vector and Direct Torque Control, Oxford, U.K.: Oxford Univ. Press, 1998.

[13] D. Casadei, G. Serra, A. Tani, Implementation of a Direct Torque Control Algorithm for Induction Motors based on Discrete Space Vector Modulation, IEEE Trans. Power Electron., Vol. 15, N. 4, pp. 769-777, July 2000. 